Tropical Journal of Pharmaceutical Research October 2019; 18 (10): 2003-2010

ISSN: $1596-5996$ (print); 1596-9827 (electronic)

(c) Pharmacotherapy Group, Faculty of Pharmacy, University of Benin, Benin City, 300001 Nigeria.

\title{
Development of Ficus religiosa extract-loaded emulsion system for topical application: Characterization and stability evaluation
}

\author{
Irfan Aslam*, Naveed Akhtar \\ Department of Pharmacy, Faculty of Pharmacy and Alternative Medicine, The Islamia University of Bahawalpur, Bahawalpur \\ 63100, Pakistan \\ ${ }^{*}$ For correspondence: Email: irfanaslam.iub@gmail.com; Tel: 0092-3116615424

\begin{abstract}
Purpose: To develop, optimize and characterize a topical (W/O) emulsion containing $4 \%$ Ficus religiosa extract for cosmeceutical purposes.

Methods: The ethanol extract of Ficus religiosa was obtained by Soxhlet method. Various formulations were developed using paraffin oil, emulsifier (Abil(B-EM 90) and purified water at different proportions, and their physical stability was assessed under different stress conditions, to enable selection of the most stable formulation. The optimized formulation based on stability studies was chosen for evaluation of different physical properties, i.e., color, liquefaction, phase separation, centrifugation, $\mathrm{pH}$, droplet size and rheology, under accelerated conditions for 12 weeks.

Results: The optimized formulation (F4) contained ethanol extract (4.0\%), Abil(B-EM 90 (3.5\%), paraffin oil (14.0\%) and purified water (78.5\%), and remained stable on centrifugation under all stress conditions. The $\mathrm{pH}$ of the formulation remained within the specified range for human skin $\mathrm{pH}$ i.e. 4.5 6.0, and droplet size of dispersed phase also persisted within the size range of macroemulsion (1 - 100 $\mu m$ ) throughout the study period. Rheological properties of the formulation showed shear thinning response, and flow index value less than 1 resulted in pseudoplastic flow of emulsion.

Conclusion: These results suggest that the optimized emulsion system was stable and can serve as a good medium for topical delivery of various natural substances.
\end{abstract}

Keywords: Ficus religiosa, Emulsion, Abißß-EM 90, Rheology, Stability

This is an Open Access article that uses a fund-ing model which does not charge readers or their institutions for access and distributed under the terms of the Creative Commons Attribution License (http://creativecommons.org/licenses/by/4.0) and the Budapest Open Access Initiative (http://www.budapestopenaccessinitiative.org/read), which permit unrestricted use, distribution, and reproduction in any medium, provided the original work is properly credited.

Tropical Journal of Pharmaceutical Research is indexed by Science Citation Index (SciSearch), Scopus, International Pharmaceutical Abstract, Chemical Abstracts, Embase, Index Copernicus, EBSCO, African Index Medicus, JournalSeek, Journal Citation Reports/Science Edition, Directory of Open Access Journals (DOAJ), African Journal Online, Bioline International, Open-J-Gate and Pharmacy Abstracts

\section{INTRODUCTION}

Plant materials have been in use since ancient times due to their nutritional, cosmetic and therapeutic potential. It has been established in various studies that oral intake or topical administration of plant extracts improves skin integrity and appearance by reducing degenerative disorders and other skin-related issues such as inflammation, cancers and aging [1]. Plant material-based preparations naturally have multiple properties like anti-oxidant, antiinflammatory, anti-microbial and nucleic acidrepair effects against various dermatological disorders i.e., sunburn, cancer and aging. These effects may be due to the presence of 
antioxidants, vitamins, terpenoids, essential oils, proteins, and other bioactive compounds [2].

The plant Ficus religiosa is available all over the world. The plant is rich in several medicinal constituents which account for its use in the treatment of different diseases such as asthma, cough, diarrhea, diabetes, migraine, and skin disorders [3]. Its therapeutic potential against contagious diseases, disorders of microbial origin, epilepsy, gastro-intestinal problems, inflammation, menstrual disorders, respiratory problems, stress and seizure have been reported [4]. Moreover, it has significant antiviral, antineoplastic and anti-ulcer properties [5].

Emulsions are two immiscible phase systems in which one phase in the form of globules is evenly distributed throughout the other phase (continuous phase) in the presence of a stabilizing agent of suitable HLB value. Emulsions can be developed in different forms such as macroemulsions, microemulsions and multiple emulsions. They may be water-in-oil $(\mathrm{W} / \mathrm{O})$ or oil-in-water (O/W) types, depending on the nature of the stability enhancers used. Emulsions are widely used in pharmaceutical, cosmetic, agriculture, food and petroleum industries. The ultimate goal of developing pharmaceutical emulsions for topical application is to promote spreadability and bioavailability of the constituents [6].

In this present work, Ficus religiosa extractbased W/O emulsions were developed and optimized for cosmeceutical purposes. For the selection of optimum formulation, different proportions of ingredients were used to develop various formulations which were stored under different stress conditions. The physical stability of the optimized formulation was evaluated at different study conditions for the period of 12 weeks.

\section{EXPERIMENTAL}

\section{Materials}

Fresh leaves of Ficus religiosa were collected in July and August, 2014 from the rural areas of Bahawalnagar District, Punjab, Pakistan. They were identified by Dr. Saeed Pirzada, a specialist taxonomist from Cholistan Institute of Desert Studies (C.I.D.S.), Islamia University Bahawalpur, Pakistan. A specimen sample was preserved in the herbarium (voucher no. IUBC.I.D.S.-3514), for future reference. Ethanol and paraffin oil were acquired from Merck KGaA, Germany. Abil ${ }^{\circledR}$-EM 90 was purchased from Franken Chemicals, Germany. Double distilled, deionized water was obtained fresh from Central Research Laboratory of Pharmacy Department.

\section{Preparation of botanical extract and its emulsion system}

The plant material was shade-dried at ambient temperature for eight weeks to accomplish complete dryness. The dried material was pulverized and ground to obtain homogeneous particle size. The resultant powder (400 g) was packed in Soxhlet apparatus under reflux on a water bath, and extracted with $800 \mathrm{~mL}$ of ethanol [7]. The extract was filtered through filter paper (Whatman No. 45), and subjected to solvent evaporation at $45^{\circ} \mathrm{C}$ in a rotary evaporator (Heidolph, Laborota 4000, Germany). The resultant extract was stored in refrigerated in a closed container prior to use.

Emulsion (water-in-oil) was formulated using previously reported method, with slight modifications [8]. Emulsification of both oil and aqueous phases was carried out with the help of an emulsifying agent i.e. $\mathrm{Abil}^{\circledR}-\mathrm{EM}$ 90. The aqueous phase was developed by incorporating the ethanolic extract of the plant in double distilled deionized water at $70-80{ }^{\circ} \mathrm{C}$. The oil phase was prepared by dissolving $\mathrm{Abil}^{\circledR}$-EM 90 in paraffin oil at $70-80{ }^{\circ} \mathrm{C}$. The aqueous phase was poured drop-wise into the oily phase, with continuous stirring on mechanical stirrer (IKA, Werke, Germany). The speed and stirring time were reduced in sequential manner i.e. 2,000 rpm for 15 - $20 \mathrm{~min}$, and 1,500 rpm for $10 \mathrm{~min}$. Finally, the emulsion was cooled to room temperature while further reducing the stirring speed to $500 \mathrm{rpm}$ until a homogeneous, semisolid emulsion was obtained. For preliminary trial, 30 formulations (F1 - F30) of W/O emulsion were prepared with $4 \%$ plant extract, with variable contents of paraffin oil (14 - $22 \%$ ) and Abil ${ }^{\circledR}$-EM 90 (2 - $\left.4.5 \%\right)$ as shown in Table 1.

The prepared formulations (F1 - F30) were placed at $40^{\circ} \mathrm{C}$ in an incubator (Panasonic, Model: Ml-154-PE, Japan) for 6 weeks. During this period, the formulations were analyzed for variations in color, odor, phase separation and liquefaction. After this initial stress test, the stable formulations were placed in an incubator at $8{ }^{\circ} \mathrm{C}$ for 2 weeks to select the most stable formulation with optimum concentrations.

\section{In vitro characterization of formulations}

\section{Determination of emulsion type}

Two approaches were adopted for characterization of the emulsions i.e. dilution 
method and amaranth dye method. The W/O emulsion allowed oil addition. The amaranth dye (a dark red-to-purple colored water-soluble powder) was blended with test formulation, and a drop of sample was placed on glass slide, secured with a cover glass, and analyzed under a microscope. Moreover, conductivity test was carried out to confirm the type of formulated emulsions $[9,10]$.

\section{Electrical conductivity assessment}

Electrical conductivity tests were performed at room temperature to identify the formulation types i.e. water-in-oil $(\mathrm{W} / \mathrm{O})$ or oil-in-water $(\mathrm{O} / \mathrm{W})$, and to detect any kind of formulation instability like creaming, sedimentation and phase inversion with the passage of time, using Digital Conductometer (WTW-Laboratory, Germany). These tests were carried out immediately for freshly prepared formulations, and they were repeated 2, 4, 6, 8 and 12 weeks after preparation for all samples which were kept at different storage temperatures i.e. $8,25,40 \stackrel{\circ}{\circ}$ and $40 \stackrel{\circ}{\circ}+75 \% \mathrm{RH}$ (relative humidity) for the entire study period [11].

\section{Organoleptic and physical evaluations}

In this evaluation, the optimized formulation was placed under different storage settings for 12 weeks, and analyzed periodically during that period for variations in color, odor, appearance, consistency, feel on application, and formation of creaming, sedimentation, coalescence and phase separation [12].

\section{Centrifugation analysis}

Centrifugation analyses were executed for freshly prepared formulation containing Ficus religiosa extract immediately after preparation, at room temperature, using centrifugation machine (Hitachi, Germany). This was repeated after 2, 4, 6,8 , and 12 weeks of preparation.

Centrifugation tests were carried out by placing 2 $\mathrm{g}$ of the formulation kept at different storage settings i.e. $8,25,40{ }^{\circ} \mathrm{C}$ and $40{ }^{\circ} \mathrm{C}+75 \% \mathrm{RH}$, in $15 \mathrm{ml}$ centrifuge tubes and centrifuging for two cycles of $10 \mathrm{~min}$ each at 5,000 rpm. At the end of each cycle, the samples were investigated for the presence of phase separation [12].

Table 1: Composition of Ficus religiosa emulsions

\begin{tabular}{|c|c|c|c|c|}
\hline Formulation & Plant extract (\%) & Abil ${ }^{\circledR}$-EM 90 (\%) & Paraffin Oil (\%) & Purified water (\%) \\
\hline $\mathrm{F} 1$ & 4 & 2 & 14 & 80 \\
\hline $\mathrm{F} 2$ & 4 & 2.5 & 14 & 79.5 \\
\hline F3 & 4 & 3 & 14 & 79 \\
\hline F4 & 4 & 3.5 & 14 & 78.5 \\
\hline F5 & 4 & 4 & 14 & 78 \\
\hline F6 & 4 & 4.5 & 14 & 77.5 \\
\hline F7 & 4 & 2 & 16 & 78 \\
\hline F8 & 4 & 2.5 & 16 & 77.5 \\
\hline F9 & 4 & 3 & 16 & 77 \\
\hline F10 & 4 & 3.5 & 16 & 76.5 \\
\hline F11 & 4 & 4 & 16 & 76 \\
\hline $\mathrm{F} 12$ & 4 & 4.5 & 16 & 75.5 \\
\hline F13 & 4 & 2 & 18 & 76 \\
\hline F14 & 4 & 2.5 & 18 & 75.5 \\
\hline F15 & 4 & 3 & 18 & 75 \\
\hline F16 & 4 & 3.5 & 18 & 74.5 \\
\hline F17 & 4 & 4 & 18 & 74 \\
\hline F18 & 4 & 4.5 & 18 & 73.5 \\
\hline F19 & 4 & 2 & 20 & 74 \\
\hline F20 & 4 & 2.5 & 20 & 73.5 \\
\hline F21 & 4 & 3 & 20 & 73 \\
\hline $\mathrm{F} 22$ & 4 & 3.5 & 20 & 72.5 \\
\hline F23 & 4 & 4 & 20 & 72 \\
\hline F24 & 4 & 4.5 & 20 & 71.5 \\
\hline $\mathrm{F} 25$ & 4 & 2 & 22 & 72 \\
\hline F26 & 4 & 2.5 & 22 & 71.5 \\
\hline F27 & 4 & 3 & 22 & 71 \\
\hline F28 & 4 & 3.5 & 22 & 70.5 \\
\hline F29 & 4 & 4 & 22 & 70 \\
\hline F30 & 4 & 4.5 & 22 & 69.5 \\
\hline
\end{tabular}




\section{pH assessment}

The $\mathrm{pH}$ estimation studies were performed for freshly-prepared formulations immediately after they were prepared, at room temperature using a digital pH meter (WTW, Germany).Thereafter, the $\mathrm{pH}$ test was repeated at 2, 4, 6, 8 and 12 weeks for all the samples which were kept at different storage temperatures such as 8, 25, 40 ${ }^{\circ} \mathrm{C}$ and $40{ }^{\circ} \mathrm{C}+75 \% \mathrm{RH}$ for the entire study period [13].

\section{Microscopic examination}

Microscopic analyses were performed to determine changes in morphology and mean globule size in the internal phase of the formulation using optical microscope (Nikon, Tokyo-Japan) coupled to a sophisticated camera (DCM35, USB-2.0) and software (Minisee, version 1.1). These analyses were performed for freshly-prepared formulations immediately after preparation, and were then repeated after 30, 60 and 90 days of preparation for all the samples which were kept at different study conditions i.e. $8,25,40^{\circ} \mathrm{C}$ and $40^{\circ} \mathrm{C}+75 \% \mathrm{RH}$. A minute quantity of test formulation was taken on the glass slide, and diluted with the external phase, secured with a cover slip, and analyzed under 100x (oil immersion) of a light microscope [14].

\section{Rheological studies}

Rheological properties (viscosity, shear stress and shear rate) of formulations were investigated using a cone and plate type Brookfield Digital Rheometer (Model: DV III, USA). A software (Rheocalc, Version 2.6) was used for the analysis of the resultant data, with spindle CP 41 at room temperature. Rheograms were obtained at gradually increasing rotation speeds of $10-43$ rpm and shear rate of $20-86 / \mathrm{sec}$, which were retained for $10 \mathrm{sec}$ before recording of the measurements. Rheological parameters flow index (FI) and consistency index (Cl) were measured using Power law (Eq 1).

$\mathbf{T}=K \gamma^{n}$

where; $\mathrm{y}=$ shear rate, $\mathrm{T}=$ shear stress, $\mathrm{n}=$ flow index and $\mathrm{K}=$ consistency index. Viscosities and shear stresses of test formulations were determined at speeds of 50 - $95 \mathrm{rpm}$ (with 5 increments) using shear rate of $100-190 / s$ (with 10 increments). These studies were performed for freshly-prepared formulations immediately, and then repeated at 30, 60 and 90 days after preparation for all the samples which were kept at varied storage temperatures such as 8, 25, 40
${ }^{\circ} \mathrm{C}$ and $40{ }^{\circ} \mathrm{C}+75 \% \mathrm{RH}$ for the entire study period [15].

\section{Stability studies}

The optimized formulation (F4) was evaluated for stability at $8,25,40^{\circ} \mathrm{C}$ and $40^{\circ} \mathrm{C}+75 \% \mathrm{RH}$ for the study period of 12 weeks. During this study, samples were withdrawn regularly at 2, 4, 6, 8 and 12 weeks and evaluated for any changes in color, consistency, $\mathrm{pH}$, conductivity, average globule size, and rheological parameters, as well as phase separation on centrifugation.

\section{RESULTS}

\section{F4 emulsion type}

In dilution method, when few drops of water were added to the formulation, the entire volume of added water remained immiscible with the emulsion. In amaranth dye method, the dispersed phase appeared pinkish in color, with colorless continuous phase, confirming the prepared emulsion was water-in-oil $(\mathrm{W} / \mathrm{O})$ type.

\section{Conductivity}

In this study, it was observed that the developed formulation was not a good conductor of electricity, which showed that it was $\mathrm{W} / \mathrm{O}$ in nature, as confirmed through dilution method. The formulation showed non-conductive behavior with passage of time which suggested that it remained stable throughout the study period.

\section{Effect of variable conditions and time on color of F4}

There were no color changes due to variable conditions and time. It remained light green in color throughout this period. The absence of color changes indicated the stability of the formulation.

\section{Effect of variable conditions and time on liquefaction of formulation}

The formulation was stable under the entire testing conditions and period. Results on the optimized formulation ( $\mathrm{F} 4)$ revealed that there was no liquefaction at $25^{\circ} \mathrm{C}$ and $8{ }^{\circ} \mathrm{C}$ even on the last days of $12^{\text {th }}$ week. In contrast, very minute liquefaction was observed at $40^{\circ} \mathrm{C}+75$ $\% \mathrm{RH}$ and $40^{\circ} \mathrm{C}$ only in the last week of study.

\section{Phase separation}

There was no phase separation at $8^{\circ} \mathrm{C}$ and 25 ${ }^{\circ} \mathrm{C}$ throughout the study period of 12 weeks. 
However, at $40{ }^{\circ} \mathrm{C}+75 \% \mathrm{RH}$ and $40{ }^{\circ} \mathrm{C}$, a slight separation was seen in the last week of study.

\section{Centrifugation properties of F4}

Results of centrifugation assay of formulation (F4) at different temperatures and time are summarized in Table 2. The formulation showed good long-term stability because it remained stable over the entire period under variable conditions. A slight phase separation on centrifugation was observed only at $12^{\text {th }}$ week of study period at $40^{\circ} \mathrm{C}$.

\section{pH changes in F4}

Freshly-prepared emulsions had $\mathrm{pH}$ of 5.72 . The results of $\mathrm{pH}$ measurements at different storage temperatures are summarized in Table 3. Slight and continuous decreases in $\mathrm{pH}$ were seen with increases in temperature and time. Using twoway ANOVA at $5 \%$ significance level, it was found that the changes in $\mathrm{pH}$ of formulation kept at different stress conditions and at different time intervals were not statistically significant $(p>$ 0.05).

\section{Microscopic characteristics of F4}

During microscopic examination, it was observed that the globules were spherical in shape with average size range within 4.14 - $5.12 \mu \mathrm{m}$ throughout the study period under all study conditions. No major changes were seen in morphology of the globules in entire study duration as shown in Figure 1. It is evident from the photomicrographs that slight increase in globule size was seen as a function of time. Mean globule size was smaller at normal conditions, relative to accelerated storage conditions. However, the average globule size of formulation was found to be within the range of macroemulsion $(1-100 \mu \mathrm{m})$ under all storage conditions. The photomicrographs also showed that no major instability events like coalescence or Ostwald ripening were observed during entire study period under different storage conditions.
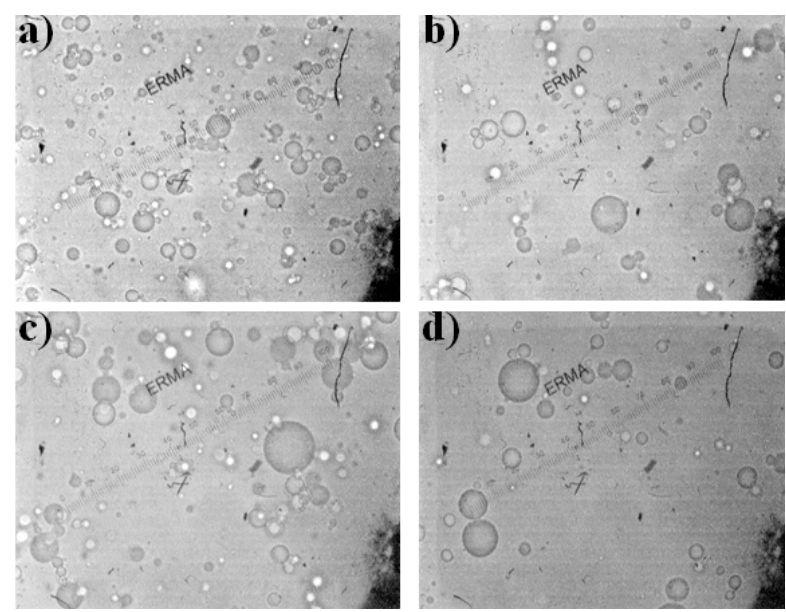

Figure 1: Microscopic examination of optimized formulation (F4) after 90 days of storage at different temperatures: (a) $8 \stackrel{\circ}{\circ}$, (b) $25^{\circ} \mathrm{C}$, (c) $40^{\circ} \mathrm{C}$, and (d) 40 ${ }^{\circ} \mathrm{C}+75 \% \mathrm{RH}$

\section{Rheological analysis}

In this analysis, rheograms showed the relationship between shear rate and shear stress at different storage conditions and at different time intervals (Figure 2). The principal rheological parameters i.e., flow index and consistency index are shown in Table 4.

Table 2: Results of centrifugation test of $\mathrm{F} 4$ at $8,25,40^{\circ} \mathrm{C}$ and $40^{\circ} \mathrm{C}+75 \% \mathrm{RH}$

\begin{tabular}{lllllll}
\hline \multirow{2}{*}{$\begin{array}{l}\text { Temperature } \\
\text { (ㄷ) }\end{array}$} & \multicolumn{7}{c}{ Age of emulsion } \\
\cline { 2 - 7 } & Fresh & 2 weeks & 4 weeks & $\mathbf{6}$ weeks & $\mathbf{8}$ weeks & 12 weeks \\
\hline 8 & $\mathrm{~N}$ & $\mathrm{~N}$ & $\mathrm{~N}$ & $\mathrm{~N}$ & $\mathrm{~N}$ & $\mathrm{~N}$ \\
25 & $\mathrm{~N}$ & $\mathrm{~N}$ & $\mathrm{~N}$ & $\mathrm{~N}$ & $\mathrm{~N}$ & $\mathrm{~N}$ \\
40 & $\mathrm{~N}$ & $\mathrm{~N}$ & $\mathrm{~N}$ & $\mathrm{~N}$ & $\mathrm{~N}$ & SPS \\
$40+75 \% \mathrm{RH}$ & $\mathrm{N}$ & $\mathrm{N}$ & $\mathrm{N}$ & $\mathrm{N}$ & $\mathrm{N}$ & $\mathrm{N}$ \\
\hline
\end{tabular}

( $N=$ no phase separation/stable; SPS = slight phase separation after 20 min)

Table 3: $\mathrm{pH}$ of $\mathrm{F} 4$ at $8,25,40^{\circ} \mathrm{C}$ and $40^{\circ} \mathrm{C}+75 \% \mathrm{RH}$

\begin{tabular}{lllllll}
\hline \multirow{2}{*}{$\begin{array}{l}\text { Temperature } \\
(\stackrel{\circ}{ } \mathrm{C})\end{array}$} & Fresh & 2 weeks & 4 weeks & 6 weeks & $\mathbf{8}$ weeks & 12 weeks \\
\hline y & 5.72 & 5.68 & 5.56 & 5.48 & 5.40 & 5.27 \\
25 & 5.72 & 5.65 & 5.50 & 5.41 & 5.38 & 5.21 \\
40 & 5.72 & 5.61 & 5.44 & 5.36 & 5.31 & 5.16 \\
$40+75 \% \mathrm{RH}$ & 5.72 & 5.57 & 5.41 & 5.30 & 5.26 & 5.11 \\
\hline
\end{tabular}


Table 4: Rheological properties of $\mathrm{F} 4$ at $8,25,40^{\circ} \mathrm{C}$ and $40^{\circ} \mathrm{C}+75 \% \mathrm{RH}$

\begin{tabular}{llcccc}
\hline $\begin{array}{l}\text { Temperature } \\
(\mathbf{- C})\end{array}$ & Rheological parameters & $\begin{array}{c}\text { Freshly } \\
\text { prepared }\end{array}$ & $\mathbf{3 0}$ days & $\mathbf{6 0}$ days & $\mathbf{9 0}$ days \\
\hline \multirow{3}{*}{8} & Consistency index & - & 413.5 & 309.8 & 222.4 \\
& Flow Index & - & 0.51 & 0.59 & 0.64 \\
& Confidence of Fit & - & 99.5 & 99.6 & 99.8 \\
25 & Consistency index & 570 & 390.5 & 302.2 & 211.8 \\
& Flow Index & 0.43 & 0.53 & 0.62 & 0.67 \\
& Confidence of Fit & 99.6 & 99.5 & 99.7 & 99.6 \\
40 & Consistency index & - & 331.3 & 247.7 & 197.7 \\
& Flow Index & - & 0.57 & 0.64 & 0.69 \\
& Confidence of Fit & - & 99.7 & 99.5 & 99.7 \\
$40+75 \% \mathrm{RH}$ & Consistency index & - & 314.8 & 226.5 & 179.2 \\
& Flow Index & - & 0.61 & 0.67 & 0.72 \\
& Confidence of Fit & - & 99.8 & 99.7 & 99.4 \\
\hline
\end{tabular}

Formulation F4 presented shear thinning response. The shear rate and shear stress were increased, but the apparent viscosity was decreased. The initial flow index value was 0.43 , with consistency index of 570 . The range of flow index was $0.51-0.64,0.53-0.67,0.57-0.69$, $0.61-0.72$ at $8,25,40{ }^{\circ} \mathrm{C}$ and $40 \stackrel{\circ}{\circ} \mathrm{C}+75 \% \mathrm{RH}$, respectively. The flow index values were not changed significantly $(p>0.05)$ with respect to temperature after storage for 12 weeks. Consistency index values were between 413.5 222.4, 390.5 - 211.8, 331.3 - 197.7 and $314.8-$ 179.2 at $8,25,40{ }^{\circ} \mathrm{C}$ and $40{ }^{\circ} \mathrm{C}+75 \% \mathrm{RH}$, respectively.
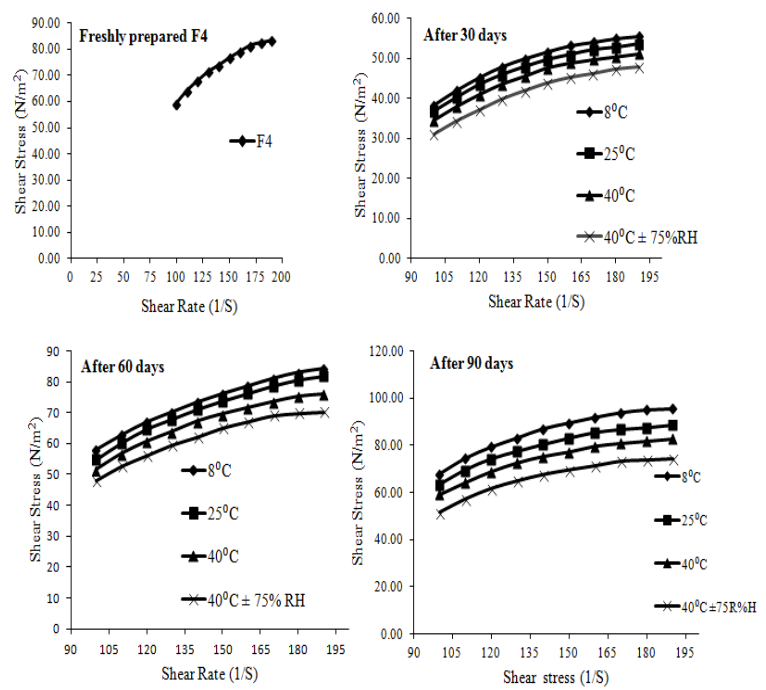

Figure 2: Shear rate vs Shear Stress curves

\section{DISCUSSION}

The quality and acceptability of emulsion systems employed in cosmetics largely depend on their physical appearance and stability profiles under all storage conditions. Electrical current promotes ionization of water as well as other added substances in a sample, and is reflected in consistency of the emulsion. Emulsion system having oil as external phase are poor electricity conductors, while emulsion systems with water as the external phase are good conductors of electricity. Therefore, the developed emulsion was stable and W/O type, since it did not conduct electricity. A similar finding was reported in previous studies in a similar manner for the confirmation of emulsion type through conductivity and dilution tests $[16,17]$.

Flow properties are highly dependent on the viscosity of the developed system. Practically, viscosity can be employed to check the quality as well as stability of macroemulsions. In such type of emulsion, due to settling of water globules, creaming occurs by forming two separate layers. Sedimentation of internal phase (water globules) is largely dependent on viscosity of the external phase as per Stoke's law. Thus, with rise in temperature, viscosity of the formulation was sequentially decreased, leading to liquefaction of the emulsion [18].

An emulsion is a biphasic, thermodynamically unstable preparation in which the density difference between dispersed and continuous phases may cause instability like creaming or sedimentation of dispersed phase under the influence of gravity, thereby resulting in phase separation. Coalescence only results when adhesive energy of globules exceeds their turbulent energy [19].

Centrifugation is a rapid technique used to estimate physical stability of developed formulations. In this technique. both phases are separated on the basis of their densities under the effect of centrifugal force. Centrifugation provokes collision of the globules as well as coalescence, thereby causing emulsion destabilization. The possible reason for the slight phase separation at the last week of study might be due to the sedimentation or creaming of dispersed globules at accelerated conditions because of gradual decline in the effect of 
surfactants with the passage of time [20]. Previous studies have also described almost similar findings through centrifugation method for induced accelerated phase separation and destabilization in prepared W/O emulsions [21]. Human skin has $\mathrm{pH}$ values ranging from $4.5-6$, and $\mathrm{pH} 5.5$ is usually considered as an average human skin $\mathrm{pH}$. Therefore, formulations intended for topical administration should have $\mathrm{pH}$ value close to that of the skin. In this study, the change in $\mathrm{pH}$ did not show much deflection from the average human skin $\mathrm{pH}$, which showed that the formulation was stable and suitable for topical application. The $\mathrm{pH}$ of topical emulsions have also been determined in previous investigations, with results similar to those obtained in the present study [22].

Microscopy is a useful technique for observing the morphology, dimensions and distribution of globules in continuous phase. It is also helpful for obtaining information regarding the causes of emulsion instability. A stable emulsion should have particles with uniform size homogenously distributed throughout the external phase. Previous studies have reported the same finding regarding the microscopic examination of emulsions [23,24].

Rheological studies are performed to examine the physical stability, flow characteristics, structural properties and deformation of semisolid formulations under stress conditions. In this study, the flow index values remained within the range of $0-1$, showing pseudoplastic behavior (non-Newtonian flow) which is an important characteristic for topical application of formulations. Similar rheological outcomes have also been depicted in a previous study [25].

\section{CONCLUSION}

The findings of this work show that the optimized water-in-oil $(\mathrm{W} / \mathrm{O})$ emulsion is highly stable under the test conditions, without alteration in physicochemical properties during the study period. Thus, the developed formulation is potentially a suitable emulsion system for topical delivery of various plant extracts as well as for dermocosmetic applications in general.

\section{DECLARATIONS}

\section{Acknowledgement}

The authors are thankful to Dr Asif Mahmood, section Head of Pharmaceutics, Faculty of Pharmacy, The University of Lahore for valuable technical assistance in this work.

\section{Conflict of interest}

No conflict of interest is associated with this work.

\section{Contribution of authors}

We declare that this work was done by the authors named in this article and all liabilities pertaining to claims relating to the content of this article will be borne by the authors.

\section{Open Access}

This is an Open Access article that uses a funding model which does not charge readers or their institutions for access and distributed under the terms of the Creative Commons Attribution License (http://creativecommons.org/licenses/by/ 4.0) and the Budapest Open Access Initiative (http://www.budapestopenaccessinitiative.org/rea d), which permit unrestricted use, distribution, and reproduction in any medium, provided the original work is properly credited.

\section{REFERENCES}

1. Ribeiro A, Estanqueiro M, Oliveira M, Sousa Lobo J. Main benefits and applicability of plant extracts in skin care products. Cosmetics 2015; 2: 48-65.

2. Aswal A, Kalra M, Rout A. Preparation and evaluation of polyherbal cosmetic cream. Pharm Lett 2013; 5(1): 8388.

3. Bhalerao SA, Sharma AS. Ethenomedicinal, phytochemical and pharmacological profile of Ficus religiosa Roxb. Int J Curr Microbiol App Sci 2014; 3(11): 528-538.

4. Singh $D$, Singh $B$, Goel $R K$. Traditional uses, phytochemistry and pharmacology of Ficus religiosa: a review. J Ethnopharmacol 2011; 134: 565-583.

5. Ghosh M, Civra A, Rittà M, Cagno V, Mavuduru SG, Awasthi $P$, Lembo $D$, Donalisio M. Ficus religiosa $L$. bark extracts inhibit infection by herpes simplex virus type 2 in vitro. Arch Virol 2016; 161(12): 3509-3514.

6. Khanum $R$, Thevanayagam $H$. Lipid peroxidation: its effects on the formulation and use of pharmaceutical emulsions. Asian J Pharm Sci 2017; 12(5): 401-411.

7. Mohsin S, Akhtar N. Formulation and stability evaluation of Bauhinia variegata extract topical emulsion. Acta Pol Pharm 2017; 74(3): 945-954.

8. Arshad Al, Khan HM, Akhtar N, Mustafa R, Aslam I, Mohammad IS. Stability assessment of polysiloxane polyalkyl polyether copolymer based cosmetic emulsion loaded with Ananas comosus extract. Lat Am J Pharm 2014; 33(8): 1363-1370.

9. Niederquell A, Machado AH, Kuentz M. A diffusing wave spectroscopy study of pharmaceutical emulsions for 
physical stability assessment. Int J Pharm 2017; 530(12): 213-223.

10. Pang B, Liu H, Liu P, Peng X, Zhang K. Water-in-oil Pickering emulsions stabilized by stearoylated microcrystalline cellulose. J Colloid Interface Sci 2018; 513: 629-637.

11. Tanriverdi ST, Yapar EA. Preparation and characterization of herbal emulsion formulations. Marmara Pharm J 2017; 21(4): 756-761.

12. Korać $R$, Krajišnik $D$, Savić $S$, Pantelić $I$, Jovančić $P$, Cekić N, Milić J. A new class of emulsion systems-Fast inverted o/w emulsions: Formulation approach, physical stability and colloidal structure. Colloids Surf $A$ Physicochem Eng Asp 2014; 461: 267-278.

13. Muhammad KW, Akhtar N, Khan HM, Mustafa R, Murtaza G. Stability study of a cosmetic emulsion loaded with Tamarindus indica seeds extract. Lat Am J Pharm 2014; 33(5): 731-738.

14. Aaen R, Brodin FW, Simon S, Heggset EB, Syverud K. Oil-in-Water emulsions stabilized by cellulose nanofibrils-The effects of ionic strength and $\mathrm{pH}$. Nanomaterials 2019; 9(2): 259.

15. Fiorotti TA, Sad CM, Castro ER, Barbosa LL. Rheological study of W/O emulsion by low field NMR. J Pet Sci Eng 2019; 176: 421-427.

16. Li XM, Zhu J, Pan Y, Meng R, Zhang B, Chen HQ. Fabrication and characterization of pickering emulsions stabilized by octenyl succinic anhydride-modified gliadin nanoparticle. Food Hydrocolloids 2019; 90: 19-27.

17. Slavova $D$, Pollak $S$, Petermann M. Phase inversion and rheological behavior of emulsions stabilized by silica nanoparticles and nanoclay. J Pet Sci Eng 2019; 177: 624-633.

18. Smaoui S, Hilima H. Application of I-ascorbic acid and its derivatives (sodium ascorbyl phosphate and magnesium ascorbyl phosphate) in topical cosmetic formulations: Stability studies. J Chem Soc Pak 2013; 35(4): 10961102.

19. Smaoui S, Hlima HB, Chobba IB, Kadri A. Development and stability studies of sunscreen cream formulations containing three photo-protective filters. Arab J Chem 2017; 10: S1216-S1222.

20. Yang $Y$, Leser ME, Sher AA, Mcclements DJ. Formation and stability of emulsions using a natural small molecule surfactant: Quillaja saponin (Q-Naturale®). Food Hydrocolloids 2013; 30: 589-596.

21. Almeida M, Charin R, Nele M, Tavares F. Stability studies of high-stable water-in-oil model emulsions. J Dispers Sci Technol 2017; 38(1): 82-88.

22. Leclercq L, Nardello-Rataj V. Pickering emulsions based on cyclodextrins: a smart solution for antifungal azole derivatives topical delivery. Eur J Pharm Sci 2016; 82: 126-137.

23. Barkhordari MR, Fathi M. Production and characterization of chitin nanocrystals from prawn shell and their application for stabilization of Pickering emulsions. Food Hydrocolloids 2018; 82: 338-345.

24. Sun J, Liu $W Y$, Feng $M Q, X u X L$, Zhou $G H$. Characterization of olive oil emulsions stabilized by flaxseed gum. J Food Eng 2019; 247: 74-79.

25. Gore E, Picard C, Savary G. Spreading behavior of cosmetic emulsions: Impact of the oil phase. Biotribology 2018; 16: 17-24. 